\title{
La política como deber. Un estudio sobre las disposiciones políticas de estudiantes argentinos de clase alta (Buenos Aires, 2011-2013)
}

\author{
Miriam Kriger ${ }^{*}$ \\ Conicet, Flacso, Universidad de Buenos Aires, \\ Buenos Aires, Argentina \\ Fuan Dukuen ** \\ Conicet, Flacso, Universidad de Buenos Aires, \\ Buenos Aires, Argentina
}

\section{RESUMEN}

Este artículo trata sobre las disposiciones políticas de jóvenes escolarizados argentinos de clase alta, presentando hallazgos de una amplia investigación realizada en escuelas de diversas clases sociales de Ciudad de Buenos Aires y Conurbano (2011-2013). Esta constó de dos instancias: una cuantitativa, en la que se aplicó un cuestionario escrito, y otra cualitativa, consistente en entrevistas individuales. Se toman elementos de ambas para explicar y comprender situadamente, desde una perspectiva bourdieuana en diálogo con la psicología cultural, la formación de disposiciones políticas. Primero se exponen datos del cuestionario que permiten relacionar la participación de los jóvenes en partidos políticos y en movimientos sociales con su condición de clase. Luego, mediante el análisis de entrevistas a jóvenes de clase alta, se trabaja la hipótesis de predominancia del esquema de pensamiento de 'ambivalencia constitutiva'. Este concilia el conflicto política/ moral en las formas de la 'buena voluntad cultural' y el 'deber de la política', evidenciando tensiones entre lo individual/lo colectivo y remitiendo al dilema moral egoísmo/altruismo. Concluimos que la aplicación de esquemas morales a la interpretación de problemas políticos genera su resolución errónea en términos de conductas morales, favoreciendo una concepción de la sociedad como sumatoria de individuos que naturaliza la desigualdad de clases.

* Doctora en Ciencias Sociales, Flacso; investigadora adjunta, Conicet-Argentina, con sede en Flacso; docente, Universidad de Buenos Aires. Correo electrónico: mkriger@gmail.com.

** Doctor en Ciencias Sociales, Universidad de Buenos Aires, UBA; becario posdoctoral, Conicet-Argentina, con sede en Flacso; docente, UBA. Correo electrónico: juanduk2002@yahoo.com.ar. 


\section{Palabras clave}

Jóvenes argentinos, clase alta, disposiciones políticas, ambivalencia constitutiva, buena voluntad cultural

Politics as a duty. A study on the political inclinations of high society Argentinean students (Buenos Aires, 2011-2013)

\section{ABSTRACT}

This article discusses the political inclinations of high society Argentinean youth. It presents the findings of extensive research in schools of different social classes of the City of Buenos Aires and the Greater Buenos Aires (2011-2013). It consisted of two stages: quantitative, where a written questionnaire was applied, and qualitative, consisting of individual interviews. Elements of both are taken to explain and understand, from Bourdieu's perspective in a dialogue with cultural psychology, the formation of political inclinations. First, we present results of the questionnaire that link the participation of youth in political parties and social movements, with their social status. Then, by analyzing interviews with young high society youth, it works the hypothesis of the predominance of the scheme of thought we call 'constitutive ambivalence', which reconciles the political/moral conflict in the forms of 'cultural goodwill' and 'political duty', highlighting the tensions between individual/collective, and referring to the moral dilemma selfishness/altruism. It is concluded that the application of moral schemes to the interpretation of political problems generates erroneous resolutions, in terms of moral behavior, favoring a perception of society as the summation of individuals that naturalizes class inequality.

\section{Keywords}

Young Argentineans, high society, political inclinations, constitutive ambivalence cultural goodwill

\section{Juventud, escolaridad y política. Antecedentes empíricos y supuestos teóricos de la investigación'}

En este artículo proponemos un análisis de las disposiciones hacia la politica en jóvenes escolarizados argentinos de clase alta, en el marco de los hallazgos de 
un estudio empírico mayor sobre la relación entre juventud, política y nación, realizado entre 2011 y 2013 entre jóvenes estudiantes $(\mathrm{N}=280)$ de siete escuelas de diferente nivel socioeconómico de Ciudad de Buenos Aires y Conurbano bonaerense. ${ }^{2}$ Nos interesa problematizar cómo intervienen la política y la moral, en tanto dimensiones cognitivas y emotivas de tales disposiciones políticas, haciendo énfasis en la condición de clase de los jóvenes, en un contexto nacional signado por conflictos y transformaciones coyunturales significativas. Nos referimos primero a los ligados al proceso de salida de la crisis tras el colapso del país en $2001,{ }^{3}$ y a las estrategias mediante las cuales en la última década las clases sociales y grupos de poder reformularon su posición en el proyecto nacional o 'proyecto común'; que particularmente en la población estudiada permite esbozar rasgos singulares de una identidad de clase ascendente. En segundo lugar, aludimos a cambios aún más recientes y amplios que interpelan a la juventud como actor social, la que irrumpe con intensa visibilidad en el espacio público, generando distintas interpretaciones, entre ellas: el 'encantamiento de lo público' por parte de los jóvenes (Aguilera Ruiz, 2011); la 'consagración de la juventud' como causa militante por parte de los adultos (Vázquez, 2013); y la 'nueva invención de la juventud' por parte de los Estados nacionales en recuperación (Kriger, 2013).

Es importante señalar que tomar como objeto de estudio el vínculo entre jóvenes y política en la Argentina contemporánea, implica tener en cuenta los procesos más amplios a nivel global que hacia finales del siglo XX generaron el desarrollo de un campo específico de estudios sobre la juventud, de carácter multidisciplinar, tanto desde un enfoque internacional (Coleman y Hendry, 2003) como latinoamericano (Duarte, 2005; Aguilera Ruiz, 2009; Chaves, 2009; Alvarado y Vommaro, 2010).

En una primera etapa, durante la década de 1990 y en pleno proceso de expansión de los procesos globalizadores con la subsiguiente pérdida de centralidad de los Estados nacionales, tal campo estuvo signado por la preocupación por la inclusión social de los jóvenes y su baja participación en la política (De Laire, 2001), postulando con amplio consenso su apatía y despolitización (Hahn, 2006; Chaves, 2005; Sidicaro, 1998). No obstante, se mostraron también prácticas alternativas que con diverso grado de politicidad emergían del campo de la cultura (Margulis, 1996; Reguillo, 2000; Urresti, 2000), los movimientos sociales (Feixa, 2000; Zibechi, 2003) y los activismos territoriales (Vázquez y Vommaro, 2008).

La investigación fue realizada en el marco de los proyectos mencionados, dirigidos por la Dra. Miriam Kriger.

3 La crisis argentina de fin de siglo fue emblemática por su profundidad, llegando en diciembre de 2001 a un estallido social conocido como el 'argentinazo' y a la destitución del gobierno por parte de la ciudadanía, con la posterior acefalía y default integral del país. 
En una segunda etapa, que comenzó con el nuevo milenio y la agudización de la crisis tras el colapso del modelo neoliberal en las diversas regiones, la tendencia se invirtió: el foco de los estudios se desplazó hacia la irrupción de los jóvenes en lo público, su mayor participación y su protagonismo en la protesta social (Dreyer y Ocampo, 2013; Kriger, 2012; Vommaro, 2013). En este giro, lo más interesante desde nuestra perspectiva es la modalidad crecientemente política que adoptó su participación, especialmente en algunos países como Argentina, Chile, Colombia, México (Vommaro, 2013), y la recuperación de ámbitos tradicionales tan rechazados previamente como los partidos políticos (Kriger, 2013; Núnez, 2012; Pérez y Natalucci, 2012), integrados crecientemente a las militancias estudiantiles reactivadas, como muestran Pérez y Natalucci (2012) y Saintout (2010) para el caso argentino. Se postula así la politización de los jóvenes, que hemos vinculado en otros trabajos (Kriger, 2010,2012) con estrategias de supervivencia y recuperación poscrítica de los proyectos nacionales.

Ahora bien: aunque existen diversos estudios que indagan estas temáticas, la afirmación tanto de una despolitización juvenil en los noventa como de una politización en la actualidad son objeto de debate tanto en su planteo teórico como en su constatación empírica, y no han sido aún lo suficientemente investigadas desde una perspectiva que permita además explicar y comprender, como dirían Bourdieu et al. (1963) y Bourdieu (1993), las condiciones sociales de posibilidad de estos procesos y de transición entre ellos, retomando la perspectiva de los propios agentes. Asimismo, señalamos que en Argentina, en particular, estas cuestiones adquieren aún mayor relevancia actual a partir del incremento de la participación juvenil en la política estudiantil y partidaria (Kriger, 2012, 2013; Núnez, 2012; Saintout, 2012), y se acentúa en el plano jurídico con la promulgación en 2012 de la Ley Nacional 26774, que adelanta la edad del voto a los 16 ańos.

En ese sentido, el análisis que presentamos busca contribuir a esa explicacióncomprensión introduciendo elementos de una línea teórica poco trabajada en el área de estudios sobre juventud y política: la sociología de Bourdieu. En consecuencia, desde una perspectiva de inspiración bourdieuana (Dukuen, 2013b), nos preguntamos por el vínculo entre capital cultural, clases sociales y disposiciones hacia la política. Esto nos permite señalar que si bien la obra de Bourdieu ha sido retomada en los últimos diez años en valiosas investigaciones latinoamericanas que trabajan la relación entre juventud y capital cultural-escolar (entre ellas Dávila, Ghiardo y Medrano, 2006; Martínez, Villa y Seoane, 2009; Brandäo, 2009; Gayo, 2013), cuando nos dirigimos al vínculo entre jóvenes y la política, en especial en el caso argentino, la presencia de esta perspectiva se vuelve marginal. De hecho, debemos señalar como excepción inspiradora en este país las investigaciones de Vázquez 
(2010, 2012, 2013), que toman como objeto a agentes o agrupaciones con prácticas 'militantes', refiriendo a la crítica de Bourdieu ([1978]1990b) respecto del uso de la categoría jóvenes -que compartimos ampliamente- ${ }^{4} \mathrm{y}$ trabajando las nociones de habitus y trayectorias. Aun así, dichas investigaciones toman como objeto a jóvenes militantes y no se ocupan ni de las disposiciones hacia la política en el marco de dominios de la práctica (Dukuen, 2013a) no específicamente militante (como el escolar) - pero que operarían como su condición de posibilidad estatutaria (Bourdieu 1979, [1980] 1990a) - ni de la configuración que presentan en jóvenes escolarizados de diferentes clases sociales, y en especial de clase alta.

Es en ese hiato donde interviene nuestro trabajo, en el que vamos a discutir hallazgos empíricos de un estudio más amplio, referidos a la relación entre a) las disposiciones de jóvenes escolarizados hacia la participación política, y b) su capital cultural-económico (Bourdieu, 1979), centrándonos en cómo se estructura tal relación entre jóvenes de clase alta, cuestión que señalamos pero no profundizamos en trabajos anteriores (Kriger y Dukuen, 2012; Dukuen, 2013b). A continuación retomaremos los supuestos teóricos que son condición de producción de este estudio.

\section{Cultura, capitales y política}

En cuanto al punto a), relativo a las disposiciones hacia la participación politica, en el estudio que realizamos se indagó la existencia de participación previa y presente en agrupaciones políticas y sociales, así como la disposición de los jóvenes a participar potencialmente en estas en el futuro. En ese sentido, consideramos la política como una dimensión central del vínculo de los ciudadanos con el 'proyecto común' (Kriger, 2010), que no se restringe a la política formal (por lo cual hemos incluido en nuestra categorización prácticas sociales no tradicionalmente políticas), pero que tampoco incluye la totalidad de las prácticas sociales, aun cuando en alguna medida todas son portadoras de politicidad. Al respecto, de acuerdo con Bonvillani et al. (2010), si bien la politización es un horizonte constitutivo de los vínculos sociales, no puede atribuirse carácter político a todo colectivo ni sistema de prácticas. Asimismo, desde una perspectiva cognitiva, consideramos que si bien todos los hombres son sujetos sociales, no todos llegan a ser sujetos políticos plenos, aunque todos sus actos tengan ineludiblemente sentidos y efectos

4 Lejos de una comprensión esencialista, la categoría de jóvenes o juventud es objeto de las luchas de clasificación que comprenden (sin ser exhaustivos) el 'campo de estudios de juventud', los partidos y agrupaciones políticas y militantes, el Estado, ciertos subcampos de producción cultural, y los agentes que se identifican/son identificados por ellas. 
políticos. Asumiendo la distinción entre ciudadanías activas y deficitaritas (Ruiz Silva, 2009), decimos que la formación de la subjetividad política -que incluye la autoconsciencia y la autocalificación- no responde a un desarrollo biológico ni espontáneo, sino a una construcción cultural, histórica y social (Kriger, 2010). Esto fundamenta el derecho de todo ciudadano a acceder a una educación política en el marco de una democracia de iguales, y ha justificado en gran medida el origen mismo de la educación estatal (Carretero y Kriger, 2004).

En relación con el punto b), la propuesta de Bourdieu en La distinción (1979) nos permite realizar algunas precisiones relativas a las especies de capital, en el marco de la estructura del espacio social, el cual se construye a partir de tres dimensiones: volumen del capital, estructura del capital y la evolución en el tiempo de ambas (Bourdieu, 1979). Brevemente señalamos que en las sociedades postindustriales el capital cultural se define especialmente por la certificación escolar, y el capital económico por el nivel de ingresos, patrimonio, etcétera. Para un análisis del espacio social y la distribución del capital, Bourdieu propone distinguir diferencias primarias que permiten establecer grosso modo las grandes clases de condiciones de existencia, que encuentran su principio en el volumen global del capital (económico y cultural). Así se va desde las clases que están mejor provistas de ambos capitales (dominantes) hasta las clases más desprovistas (dominadas). Además Bourdieu señala diferencias secundarias relativas a la estructura del capital que permiten establecer fracciones de clase según la distribución de cada especie de capital en el capital global. Por ejemplo, dentro de la clase dominante hay una fracción dominada (+ capital cultural - capital económico), compuesta por intelectuales, artistas, profesores, etcétera, y una fracción dominante (+ capital económico - capital cultural), conformada por industriales y grandes comerciantes. Lo que Bourdieu observa en las clases dominantes, entonces, es una estructura en quiasma, que se define por el tipo de estrategias de reproducción de la que depende cada fracción de clase, sea del tipo escolar o económica.

Esta referencia nos permite seńalar como antecedentes de nuestras investigaciones estudios que relacionan a) la distribución desigual de las especies de capital (económico y cultural) que permiten ubicar a un agente en una condición de clase, y b) sus disposiciones hacia la política. En el capítulo 8 de La distinción, Bourdieu (1979; Dukuen, 2013b; Nordmann, 2010; Lane, 2006; Wacquant, 2005) analiza el índice de no respuesta a preguntas 'políticas' y observa cómo este crece a medida que baja el capital cultural de los agentes. Esto implicaría una correlación fuerte entre capital cultural y disposiciones hacia la política las cuales estarían desigualmente distribuidas entre las clases en relación con las condiciones culturales de su producción y legitimación (que incluye la autopercepción y la autocalificación de los agentes como actores aptos o no para la política), cuestión que evidenciaría los 
efectos del capital cultural de tipo escolar. Bourdieu (1979) observa una correlación muy marcada entre el capital escolar y ciertas competencias que la escuela no enseña directamente, como las relativas al arte o la política. Para Bourdieu, la escuela es el lugar de un acto de institución que, mediante sus rituales y sus títulos, produce subjetiva y objetivamente diferencias y distinciones estatutarias muy marcadas, que incluye la relación con la política:

entre los efectos más ocultos del sistema escolar se encuentra el de 'nobleza obliga' [...] aquellos que están socialmente designados como competentes, como quienes tienen el derecho a la política, que es al mismo tiempo un deber, poseen mayores oportunidades de convertirse en lo que son, de convertirse en lo que les dicen que son, es decir, en competentes en política. (Bourdieu, [1980] 1990a, pp. 256-257)

De esa manera, Bourdieu produce la hipótesis de una correlación bastante marcada entre posesión de capital cultural, especialmente escolar, y disposiciones hacia la política.

En esta senda, un estudio local (Gordon y Moguillansky, 2003) analiza la participación política estudiantil universitaria, estableciendo el nivel de estudio alcanzado por los padres como indicador del nivel socioeconómico y del capital cultural -la condición de clase- con el que llegan a la universidad sus hijos. Concluye que existe una relación entre ambos: a mayor capital cultural, mayor participación política de los estudiantes. Esta hipótesis ha sido una herramienta heurística para nuestra propia investigación, y será trabajada en este artículo.

Dicho lo anterior, en lo que sigue definiremos primeramente las condiciones generales del estudio y luego describiremos los resultados con el propósito de explicar por qué se vuelve significativo estudiar el vínculo de los jóvenes de clase alta con la política. Tras un análisis de los datos cuantitativos que permite explicar relaciones, nos centraremos en la exploración de argumentos surgidos de entrevistas con los estudiantes de clase alta, que nos permitirán comprender sentidos.

\section{Explicar y comprender. Un estudio empírico sobre juventud y política}

La investigación más amplia a la que referimos aquí fue realizada entre los años 2011 y 2013, sobre una muestra de alumnos $(\mathrm{N}=280)$ de 17 y 18 ańos de edad, de ambos géneros, provenientes de siete escuelas medias de la Ciudad de Buenos Aires y Conurbano bonaerense, de diverso nivel socioeconómico: dos de nivel 
socioeconómico alto, dos de nivel medio, un bachillerato popular y dos de nivel socioeconómico bajo. Constó de dos instancias: una cuantitativa y otra cualitativa, siendo la primera un estudio descriptivo con diseño transversal, en el que se aplicó a la totalidad de la muestra un cuestionario escrito individual autoadministrable de 34 ítems. El mismo fue elaborado ad hoc para esta investigación, tomando como base una herramienta utilizada en estudios previos para indagar y correlacionar las representaciones de "Identidad, historia y proyecto" (Kriger, 2007) en una población similar, e incorporando ítems ligados a profundizar el conocimiento sobre el vínculo entre juventud y política en un contexto de creciente politización y de reconocimiento de los jóvenes como actores políticos: las significaciones y valoraciones dadas a la política (Kriger y Bruno, 2013), su presencia en los imaginarios de ciudadanía ideal (Kriger y Fernández Cid, 2011) y en las memorias del pasado reciente dictatorial (Kriger, 2011), así como las disposiciones políticas de los jóvenes (Kriger y Dukuen, 2012).

A través de los datos personales relevados en la encuesta y las características de los colegios, realizamos una categorización de los alumnos por condición de clase e indagamos en sus disposiciones hacia la política con el fin de observar la existencia de relaciones entre ambas dimensiones y desarrollar hipótesis para ser trabajadas en profundidad en la siguiente etapa.

La segunda instancia, cualitativa, se realizó sobre un grupo de 22 alumnos elegidos al azar entre los jóvenes voluntarios de cada una de las escuelas. Esta consistió en entrevistas individuales en profundidad, semiestructuradas, siguiendo los lineamientos del método clínico-crítico piagetiano (Delval, 2006), según el cual se piden justificaciones al punto de vista de los sujetos para luego ofrecer argumentos contrarios y evaluar la estabilidad de su pensamiento. La pauta de las entrevistas se basó en dos objetivos: a) profundizar la interpretación de los hallazgos empíricos de la primera parte de este estudio; en especial, la mayor disposición de los jóvenes de clase alta a la participación futura en partidos políticos, y b) indagar de qué modo esta disposición se vincula con su valoración y creencia 'en la política y los políticos' en el contexto argentino contemporáneo. De esta manera, al trabajar tanto cuantitativa como cualitativamente articulamos explicación y comprensión como una contribución al proyecto bourdieuano de superación de la oposición clásica entre métodos (Bourdieu et al., 1963; Bourdieu, 1993).

A continuación presentaremos resultados y hallazgos parciales de ambas instancias, referidos específicamente al problema planteado y provenientes solo de una escuela de clase alta $(\mathrm{N}=46)$, tomando como objeto de análisis cuatro ítems del cuestionario $(2,10,25 \mathrm{a}$ y $25 \mathrm{~b})$ y cinco entrevistas individuales del total. 


\section{Análisis de las relaciones entre capital cultural-económico y disposiciones hacia la política}

Atentos al objetivo de observar el vínculo entre disposiciones hacia la política y capital(es), y a sabiendas de los límites de un cuestionario no desarrollado originariamente según los lineamientos bourdieuanos, establecimos la condición de clase de los jóvenes de la muestra a partir de dos indicadores confiables, tratando de evitar así un alto índice de no respuesta: el nivel socioeconómico del colegio al que asisten, determinado por el barrio y por la condición público/privado (ítem 2 del cuestionario), y el máximo nivel educativo paterno (ítem 10) (Bourdieu, 1979; Gordon y Moguillansky, 2003). Un análisis de su distribución en la muestra nos permite categorizar tres escuelas (sujetos $\mathrm{N}=140)$, del total de siete de la muestra $(\mathrm{N}=280)$, como representantes-tipo de tres condiciones de clase, que se diferencian por el peso relativo del capital cultural. Ellas son: a) escuela privada de clase alta (barrio cerrado de zona norte del Conurbano bonaerense), donde el 80,4\% de los padres posee estudios terciarios/universitarios completos y el 19,6\%, secundarios; b) escuela pública con población de clases populares (zona sur del Conurbano bonaerense), donde el $3,3 \%$ de los padres posee estudios terciarios/universitarios, un 34,4\% tiene estudios secundarios y un $62,3 \%$, primarios; y c) escuela pública de un barrio tradicional de sectores medios (C.A.B.A), donde el $51,1 \%$ de los padres cuenta con estudios terciarios/universitarios, un $36,4 \%$ posee estudios secundarios y un $12,1 \%$, primarios.

Tabla $N^{\circ}$ 1: Nivel de estudio del padre según condición de clase del colegio

\begin{tabular}{|c|c|c|c|c|c|}
\hline & & NIVE & ESTUDIO D & PADRE & \\
\hline $\mathrm{CO}$ & EGIO & & & Terciario / & IOIAL \\
\hline Clase alta & $\begin{array}{l}\text { Recuento } \\
\text { \% de colegio }\end{array}$ & $\begin{array}{c}0 \\
, 0 \%\end{array}$ & $\begin{array}{c}9 \\
19,6 \%\end{array}$ & $\begin{array}{c}37 \\
80,4 \%\end{array}$ & $\begin{array}{c}46 \\
100,0 \%\end{array}$ \\
\hline Clases nonulares & Recuento & 38 & 21 & 2 & 61 \\
\hline & $\%$ de colegio & $62,3 \%$ & $34,4 \%$ & $3,3 \%$ & $100,0 \%$ \\
\hline Clace media & Recuento & 4 & 12 & 17 & 33 \\
\hline & $\%$ de colegio & $12,1 \%$ & $36,4 \%$ & $51,5 \%$ & $100,0 \%$ \\
\hline
\end{tabular}

Fuente: elaboración propia a base del cuestionario aplicado.

En cuanto a la participación política (que analizaremos en el apartado siguiente), hemos tomado dos ítems, el 25a: "Participaste, participas o participarías de un partido político?" y una "opción negativa absoluta", más el 25b "PParticipaste, participas o participarías de un movimiento social?" y una "opción negativa absoluta". 
En ambos casos, se indaga la existencia de experiencias previas y presentes de participación, así como la disposición a participar potencialmente y su negativa absoluta.

En relación a la pregunta $25 \mathrm{a}$, sobre participación en un partido político, los resultados obtenidos por colegio/condición de clase son los siguientes: Participó: colegio privado de clase alta: $0 \%$; colegio público de clases populares: $3,3 \%$; colegio público de clase media: 6,1\%. Participa: 2,2\%, 4,9\% y 3,0\%, respectivamente. Participaria: $30,4 \%, 19,7 \%$ y 9,1\%, respectivamente. Opción negativa absoluta: $67,4 \%, 72,1 \%$ y $81,8 \%$, respectivamente.

Tabla N²: Participación en un partido político por colegio/condición de clase

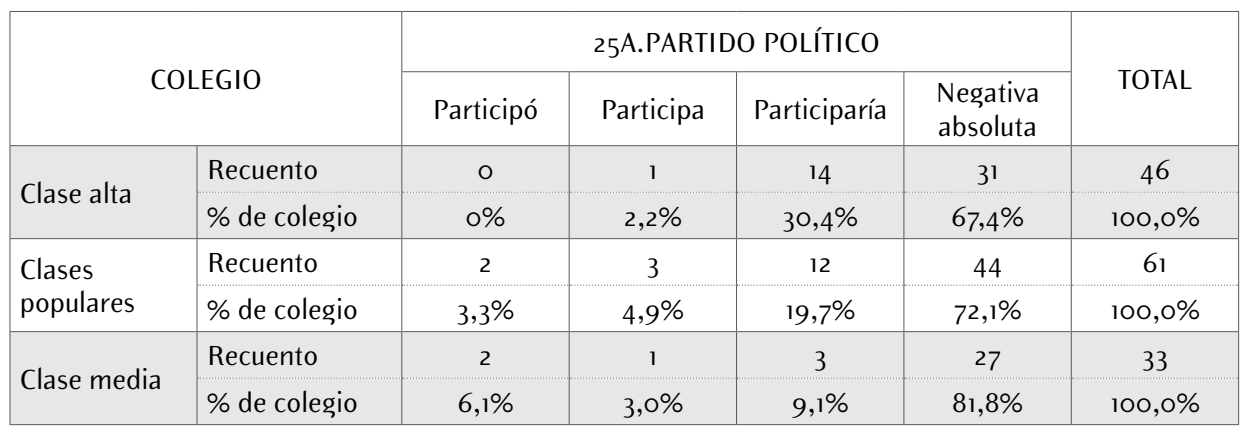

Fuente: elaboración propia a base del cuestionario aplicado.

En relación a la pregunta 25b, sobre participación en un movimiento social, los resultados obtenidos por colegio/condición de clase son los siguientes: Participó: colegio privado de clase alta: $4,3 \%$, colegio público de clases populares: 6,6\%, y colegio público de clase media: 6,1\%. Participa: 8,7\%, 3,3\% y 9,1\%, respectivamente. Participaria: $34,8 \%, 21,3 \%$ y 21,2\%, respectivamente. Opción negativa absoluta: $52,2 \%, 68,9 \%$ y $63,6 \%$, respectivamente.

Tabla $N^{\circ}$ 3: Participación en un movimiento social por colegio/condición de clase

\begin{tabular}{|c|c|c|c|c|c|c|}
\hline & & & 5B.MOVIM & NTO SOCIAL & & \\
\hline & EGIO & & & & Negativa & TOTAL \\
\hline בtלlace & Recuento & 2 & 4 & 16 & 24 & 46 \\
\hline Clase alla & $\%$ de colegio & $4,3 \%$ & $8,7 \%$ & $34,8 \%$ & $52,2 \%$ & $100,0 \%$ \\
\hline Clases & Recuento & 4 & 2 & 13 & 42 & 61 \\
\hline populares & $\%$ de colegio & $6,6 \%$ & $3,3 \%$ & $21,3 \%$ & $68,9 \%$ & $100,0 \%$ \\
\hline Clase media & Recuento & 2 & 3 & 7 & 21 & 33 \\
\hline Clase meald & $\%$ de colegio & $6,1 \%$ & $9,1 \%$ & $21,2 \%$ & $63,6 \%$ & $100,0 \%$ \\
\hline
\end{tabular}

Fuente: elaboración propia a base del cuestionario aplicado. 
Uno de los primeros resultados que se desprenden del análisis es la baja presencia de disposiciones tanto hacia la participación en partidos políticos como en movimientos sociales, signada por la alta negativa absoluta a las tres posibilidades de participación, la cual atraviesa claramente a los colegios-condiciones de clase. En este punto, comparativamente los porcentajes son los siguientes: colegio privado de clase alta: $67,4 \%$ partido político; $52,2 \%$ movimiento social. Colegio público de clases populares: $72,1 \%$ y $68,9 \%$, respectivamente. Colegio público de clase media: $81,8 \%$ y $63,6 \%$, respectivamente, siendo el punto máximo de negativa respecto a partido político el colegio de clase media $(81,8 \%)$ y respecto a movimiento social, el de clases populares (68,9\%). Esto nos muestra que cuando pasamos de partido político a movimiento social la ausencia de disposición disminuye a través de las clases: superando la negativa en $18,2 \%$ en el colegio de clase media; $15,2 \%$ en el colegio de clase alta y $3,2 \%$ en el de clases populares. Esto significa que, como mostramos en un artículo anterior (Kriger y Dukuen, 2012), hay una mayor negativa general hacia la participación en partidos políticos que en movimientos sociales, destacándose el hecho de que la distinción entre ambas disminuye drásticamente en el caso del colegio de clases populares $(3,2 \%)$. Vale señalar que la baja participación política que encontramos y que atraviesa a todas las clases, coincide con lo señalado para el nivel universitario por Delfino y Zubieta (2011). En ese sentido, la encuesta como técnica permite cuestionar las evidencias de sentido común, en este caso sobre la percepción de una intensa y extensa politización juvenil, que podría verse distorsionada en el marco de un proceso epocal de 'consagración de la juventud' (Vázquez, 2013), que estaría menos ligado con la propia intervención de la juventud en el campo político que con la consagración de los adultos de la condición juvenil.

Es en la participación política de los jóvenes en el caso de la 'participación futura' donde los porcentajes crecen, en especial en los jóvenes de clase alta: colegio de clase alta: 30,4\% partido político, 34,8\% movimiento social. Colegio de clases populares: $19,7 \%$ y $21,3 \%$, respectivamente. Colegio de clase media: $9,1 \%$ y $21,2 \%$, respectivamente. Además, señalamos que en términos generales las disposiciones crecen en ambos casos, y comparativamente cuando la participación se refiere a movimientos sociales.

Como vemos, en todas las clases sociales se prefiere el movimiento social al partido, lo cual puede interpretarse como una mayor impronta de lo políticoinstituyente sobre la política-instituida (Lefort, 1992) o de las formas de participación directa propias de la 'democracia de implicación' y 'de intervención' sobre las representativas asociadas al sistema político-estatal propias de la 'democracia de expresión’ (Rosanvallon, 2006). También puede entenderse como un rasgo juvenil 
de preferencia de espacios más informales y cercanos a su experiencia de vida, o como una persistencia del distanciamiento de la política tradicional, profundizado en la década de 1990. No obstante, esta diferencia es notablemente menor y no significativa solo entre los jóvenes de clase alta, en particular en la disposición futura $(30,4 \%$ y $34,8 \%)$, lo cual podría estar indicándonos que la política tiene una mayor legitimidad en ese grupo, cuyas razones interpretamos a partir de las entrevistas realizadas en la segunda instancia del estudio.

Aunque en este artículo nos centraremos en el caso de los jóvenes de clase alta, entendemos que la diferenciación entre las disposiciones a la participación futura en un partido político entre el colegio de clases populares (19,7\%) y media $(9,1 \%)$ es un hallazgo que permite repensar y matizar la relación determinante entre capital cultural y disposiciones políticas inspirada en Bourdieu, como lo hemos señalado en artículos anteriores (Kriger y Dukuen, 2012; Dukuen, 2013b). De hecho, el colegio de clase media presenta el porcentaje más bajo $-\mathrm{y}$ no el de clases populares como cabría esperar desde esa hipótesis-, lo cual nos señala que la ausencia o presencia del capital cultural no sería un factor explicativo-comprensivo determinante en sí, sino que cobraría sentido solo en su vínculo estructural-relacional con otros capitales (más o menos legítimos) que pueden articularse con él, e incluso sustituirlo (Dukuen, 2013b).

Esta diferencia es lo que de alguna manera observamos en los jóvenes de clase alta, donde efectivamente podemos comprender la importancia de la reproducción del capital cultural vía inversión en una trayectoria educativa determinada, y su contribución a la incorporación de disposiciones hacia la política. Por eso mismo, el hallazgo empírico que queremos destacar en este artículo, y que conecta de manera directa con la hipótesis de Bourdieu sobre la correlación entre capital cultural y disposiciones hacia la política, refiere a que el índice más alto de 'participación futura' en partido político y movimiento social aparece en los jóvenes del colegio de clase alta, mostrando escasa diferencia entre ellas. En este caso, podemos hipotetizar que estamos frente a una de las formas que adopta la 'buena voluntad cultural', caracterizada como reconocimiento más que conocimiento o práctica de la cultura legítima -que en el caso estudiado por Bourdieu (1979) caracteriza a las burguesías en ascenso-, en la cual la participación política y social son ideal y legítimamente positivas como horizonte posible de clase en una sociedad democrático-liberal, pero que en tiempo presente y en forma activa se diferencian con claridad en la instancia cuantitativa de nuestro estudio, siendo el porcentaje de participación presente: $2,2 \%$ partido político y $8,7 \%$ movimiento social. Todo esto nos llevó a indagar en profundidad en la instancia cualitativa acerca de la forma en que se expresan en el discurso verbal las disposiciones hacia la política en los jóvenes escolarizados de clase alta. 
Comprender: una interpretación de las entrevistas a jóvenes de clase alta en torno a 'la política'

El análisis de las cinco entrevistas a estudiantes de la escuela de clase alta, ${ }^{5}$ nos ha permitido desarrollar una interpretación sobre la forma particular en que se expresan sus disposiciones hacia la política. Como punto de partida hemos propuesto una hipótesis exploratoria proveniente del campo de la psicología cultural, que señala la existencia de un conflicto entre pensamiento político y juicio moral, que se expresa como ambivalencia constitutiva (Kriger, 2007) en los esquemas de pensamiento de los jóvenes. Se trata de un dinámica de adecuación que aplicamos específicamente al pensamiento sobre la nación, y que consiste en la copresencia de elementos conceptualmente contradictorios que se interconstituyen en su diferencia, generando conciliaciones que obstaculizan la percepción del conflicto cognitivo, pero favorecen la identificación e integración al nosotros nacional (Kriger, 2010). En el presente artículo trasponemos esa ambivalencia en términos bourdieuanos, en el marco de una 'buena voluntad cultural' y un 'deber de la política' (Bourdieu, 1979) que la situación de entrevista como interpelación necesariamente 'artificial' contribuye a poner de relieve cuando se la toma como objeto de análisis (Bourdieu, 1993).

A la hora de realizar el estudio empírico, observamos un primer índice del orden de las prácticas, el que consideramos no debía ser pasado por alto, ya que es indicativo de la relación 'subjetiva' de estos jóvenes de clase alta con 'la política': ante nuestro llamado a realizar las entrevistas y a sabiendas de la temática de las mismas, los estudiantes en general (entre los cuales luego elegimos solo cinco al azar) exhibieron un gran interés en participar. Siguiendo a Bourdieu, este fue un primer indicio práctico de que frente a la política se autopercibían como aquellos que "están socialmente designados como competentes, como quienes tienen el derecho a la política, que es al mismo tiempo un deber" (Bourdieu, [1980] 1990a, p. 257). Podemos ver ahí una de las formas que adquiere el "deber de la política" como efecto de "nobleza obliga" al cual la escuela contribuye en el orden de las prácticas, incorporando el sentimiento de autolegitimación -también llamado por Bourdieu "competencia social"- en los nuevos "herederos" ([1980] 1990a, pp. 256257). Siendo allí objeto de inversión en la adquisición/reproducción de un capital cultural escolar, se encuentran potenciados por un proceso de reconstrucción poscrítica, en el que se le otorga un rol central a la dimensión identitaria y al rescate de la nación/lo nacional como proyecto común a heredar/continuar por parte de

5 Una versión preliminar (Kriger y Dukuen, 2013) fue presentada como ponencia en el IV Congreso Internacional de Investigación Educativa. Universidad Nacional del Comahue, el 1 de noviembre de 2013. 
los jóvenes, según constatamos en nuestras investigaciones recientes (Kriger, 2012; Kriger y Bruno, 2013; Kriger y Dukuen, 2012; Kriger y Fernández Cid, 2011).

De hecho, desde un enfoque institucional, el director del establecimiento se mostraba interesado en que los jóvenes participaran, fuesen críticos y discutieran entre sí sobre 'política', todo lo cual encontraba un correlato en las prácticas pedagógicas propiamente escolares. Agréguese a esto que mientras realizábamos la encuesta pudimos observar en la escuela el desarrollo de una actividad de formación político-democrática; puntualmente, un simulacro de elecciones mediante el cual cada aula debía armar 'partidos políticos' con plataformas, participar de debates y presentarse a elecciones.

También esta escuela -en línea con la mayoría de los establecimientos que conforman la clase alta en barrios privados y countries- proyecta e impulsa actividades solidarias y filantrópicas de asistencia a sectores 'desfavorecidos' (Ziegler, 2004; Del Cueto, 2007), lo cual no es un dato menor, ya que ubica subjetiva y objetivamente a los jóvenes en una posición en el espacio social, y en una toma de posición frente a sí y los otros sociales de clase.

Esta combinación entre el aprendizaje escolar del ejercicio de la democracia liberal mediante el voto y la solidaridad asistencial con los 'otros' de otras clases, podrían ser pensados como formas prácticas de ejercicio de 'la buena voluntad cultural' (Bourdieu, 1979) de las burguesias en ascenso, que conforman a 'los que ganaron' (Svampa, 2001) en la década de 1990 en Argentina, y que son quienes pueblan los barrios cerrados y countries creados en los últimos 25 años (Del Cueto, 2007), como es el caso que estamos analizando. Entendemos que las prácticas señaladas contribuyen a incorporar en los jóvenes disposiciones relativas a lo que Bourdieu (1977) concibe como una 'integración moral', concepto que fundamenta un 'porvenir de clase y una causalidad de lo probable' en clave propia (Bourdieu, 1974) sin perder de vista que cada habitus particular es una variante estructural de un habitus de clase: en las entrevistas pudimos observar que los 'jóvenes' se identifican con una trayectoria educativa y profesional en común y con apuesta a largo plazo en universidades privadas con la que la escuela tiene vínculos. El caso ejemplar se observa cuando dos de los entrevistados mencionan su vocación y proyecto de seguir la carrera de Ciencias Políticas en dos universidades privadas y de elite, señalando que estaban muy interesados en 'la política':

F: A mi me interesa mucho la politica, voy a estudiar Ciencias Politicas.

Entrevistador (E): ¿Dónde?

F: En San Andrés. (F., 18 años) 
I: Yo voy a estudiar Ciencias Políticas, y también está la carrera de Relaciones Internacionales, que es casi lo mismo; cambia el último año nada más. E: ¿También en San Andrés?

I: No, voy a ir a la UCA. (I., 18 años)

En este punto en que muestran una absoluta certeza subjetiva sobre el porvenir es donde encuentra un grado de evidencia empírica la conocida tesis de Bourdieu et al. (1963) y Bourdieu (1979), que señala que la distancia con la necesidad y con las urgencias económicas propias de una condición de clase burguesa habilitan el carácter proyectivo de la conciencia y la adquisición de disposiciones escolásticas para tomar el futuro como objeto de reflexión y de objetivación en tanto proyecto subjetivo. De hecho, es uno de los factores que contribuirían a explicar y comprender la creciente disposición hacia la política en estos jóvenes, mayormente bajo la forma de 'interés' y de 'deber ciudadano' más que de práctica concreta. De hecho, la 'naturalidad' con que los estudiantes discurren verbalmente sobre su porvenir de clase en el marco de un largo plazo en el que se ven formándose profesionalmente en la universidad y adquiriendo las responsabilidades de un 'buen ciudadano' ( $y$ entre las cuales se encuentra el 'interés en la política') no encuentra lugar para la duda o la contingencia. Detengámonos en las palabras de uno de los estudiantes que proyecta realizar la carrera de Ciencias Políticas:

E: Para vos, cuando te dicen "política", ¿qué pensás?, ¿con qué lo asociás? I: Yo qué sé, con armar el país. O con ayudar, en realidad, más que todo. Con ayudar a que cambien las cosas.

E: $O$ sea asociás la política con un significado, en primer lugar, positivo. I: $Y$, si. Es más, sí, quiero estudiar eso.

E: Digamos, tenés confianza en la politica.

I: Sí.

E: ¿Y dirias lo mismo de los politicos?

I: No. Yo qué sé, creo que hay, pero no son los más conocidos. No me identifico con ningún gran partido político, tampoco.

E: Pero hay gente que te dice: "Yo no confio en ningún politico. Te metés en política y ya sos corrupto”. ¿Vos qué opinás de eso? 
I: No, yo creo que no. Es más, al revés, si pensara asi no estudiaría... estudiaría algo nada que ver. Pero tampoco creo que... todos me dicen: "ique vas a estudiar Ciencias Politicas!, ¿vas a ser presidente? No, nada que ver. Pero yo qué sé. Los diputados, por ejemplo, tienen mucho más de lo que yo me gustaría ser que los lideres politicos. (I., 18 años)

Si bien el interés en la política y su valoración positiva es una constante en todas las entrevistas y, a diferencia de la anterior con su futuro colega que no expresó interés en ser un 'político de profesión', aquí se observa un acercamiento a la posibilidad de una práctica concreta que diferencia la función ejecutiva de la legislativa, y que puede relacionarse con una concepción solidaria, pero no política, sino negadora de la misma en tanto no puede reconocer su dimensión conflictiva. Del mismo modo, 'ayudar a armar el país' implica no identificarse con ningún partido político (y por ende, con ninguna construcción propiamente política), sino con el 'bien común' (percibido desde un enfoque individualista). Por ello podemos preguntarnos cuál es el sentido de la diferenciación valorativa entre la función política ejecutiva y la legislativa, algo que puede derivarse de cómo este joven define la política como profesión, frente a la negativa a estudiar 'abogacía':

\section{E: ¿Y qué opinan en tu medio de tu elección?}

I: $Y$, por ejemplo, en mi familia todos me dicen: "Tenés que estudiar abogacía y después... pero yo no quiero ser abogado. Yo les decía: "El abogado siempre se para de un lado de los dos y trata de convencer de que lo de él es lo correcto. Y la politica es el consenso entre ambas partes para el bien común". (I., 18 años)

La concepción 'solidaria' de la política como 'consenso para el bien común' es la forma en que el joven interpreta la función legislativa, mediante la cual se presentan proyectos de ley, se debate, se realizan modificaciones, etcetéra, frente a la función ejecutiva, mediante la cual aparece el 'líder político' (el presidente), como una posición de mando ligada, por comparación, a la imposición del punto de vista del entrevistado. Veremos a continuación que en el discurso de los jóvenes, el consenso y el bien común puestos del lado de 'la política' se muestran como la contracara altruista frente al 'egoísmo' y el beneficio propio de 'los políticos'. Por eso mismo, allí donde aparece el 'consenso para el bien común', encontramos que en todos los entrevistados 'la política' es altamente valorada, si bien ello disminuye cuando pasamos del plano moral (el deber ser y el bien común) al de las prácticas políticas propiamente dichas (lo que recuerda 'las manos sucias', de Sartre), donde 
se presentan las dificultades de gobernar y se las relaciona con defectos morales como 'la mentira' y 'la corrupción'. Este extracto de otra entrevista ilustra el movimiento que va desde la política como algo positivo hasta las prácticas políticas y sus agentes -los políticos- como algo negativo:

E: ¿Vos qué opinás de la politica? Como concepto. ¿Con qué lo asociás? $R$ : Lo asocio más con el manejo del país, de los recursos tanto materiales como de leyes. Es como lo fundamental, es como lo que hace andar más o menos al país. La politica me importa mucho. Creo eso.

E: $O$ sea, ¿la pensás positivamente?

R: Claro, si. Pero, al mismo tiempo, veo como que la politica de hoy en día, en general, es como que ensucia un poco el nombre. Tanta corrupción, tanta mentira, es como que está generando un distinto concepto de politica, como de encubrir las cosas. Bueno, cosas que uno se entera como que traicionan un poco el nombre política en sí o democracia. Como que tiene dos lados: el lado bueno de gobernar y el bien común y, por otro lado, el egoísmo propio de las personas que gobiernan. Es como que depende de quién esté ejerciendo la politica.

E: ¿Distinguirías entre la política y los politicos?

R: Claro, si. Para mí, la politica es algo positivo, algo que hace bien. Pero los políticos, generalmente, veo que no... que están buscando su propio bien. (R., 18 años)

La apelación recurrente en los discursos de los entrevistados a la idea de bien común o 'el bien para todos', para designar aquello propio de la política y que debería guiar las prácticas políticas de los políticos, recuerda en su propia tensión y de manera fallida ese 'interés por el desinterés', que consiste en mostrarse desinteresados por el interés particular (Bourdieu, 1994) e interesados por el bien común. Esto se ve en la respuesta que un entrevistado da frente a la pregunta por la relación entre política y políticos:

E: ¿Distinguirías entre la política y los políticos?

R: Para mi el problema son los politicos, no la politica. Los mismos politicos que actúan no son conscientes de lo que son. Para mi, ellos buscan tener ganancias, no sé, beneficiarse de tal manera, y no se dan cuenta de que en realidad son la cabeza del país y tienen que buscar el bien para todos. (R., 18 años) 
Este fragmento, que distingue entre la política como herramienta y los usos que les pueden dar los políticos, coincidiendo con resultados de la instancia cuantitativa de este estudio (Kriger y Dukuen, 2012; Kriger y Bruno, 2013), puede ser comprendido por medio de las entrevistas, indagando en las razones que lo fundamentan. Ahora bien, esta suerte de reivindicación de la política presenta visos de redención moral sobre la base del dilema egoísmo-interés propio versus altruismo-interés común, de modo tal que los actos desinteresados y el 'interés por el desinterés', son justamente un 'doble juego' que los jóvenes no alcanzarían a vislumbrar cuando moralizan las prácticas políticas y las reducen a la obtención o no de ganancia económica. De hecho, el 'interés por el desinterés' es una forma de interés y de 'ganancia' propiamente simbólica, en la medida en que está en el fundamento del reconocimiento, que es uno de los capitales políticos por antonomasia en campos que se fundan en la negación del interés económico (como el artístico, el político), pero que indirectamente lo legitiman. Lejos de ello, observamos que cuando incorporamos la pregunta por los políticos, la valoración y la creencia caen notablemente, siendo en general negativas, aunque también generando en ese déficit el propio ideal de los jóvenes relativo a la relación distanciada entre ciudadanía y política:

\section{E: Si vos tuvieras que pensar en un ciudadano ideal, ¿sería un tipo que se mete en politica o no? \\ T: Totalmente, que le interesa a full. Me parece un gran problema de Ar- gentina que todos dicen: "Que lo haga otro". (T., 18 años)}

Pero el 'doble juego', propio del 'interés por el desinterés' que atraviesa con diferentes variables el campo político -y los campos de producción cultural en general-, encuentra su punto de remate y su imposibilidad misma en el discurso de estos jóvenes, ya que se fundamenta en una ambivalencia constitutiva (Kriger, 2010) que si bien les permite (a ellos, para sí) conciliar la tensión entre la política y la moral en su pensamiento, la vuelve más evidente como conflicto (para nosotros) al analizar su discurso. Por un lado, el marcado interés por la política se encuentra con el ideal de ciudadano que proponen. En este punto, estos jóvenes en particular se piensan a sí mismos como ciudadanos diferentes (con 'las manos limpias'): responsables, honestos, conscientes del deber público (el bien común) y de su lugar distintivo en la sociedad. Por el otro lado, está la política encarnada como práctica de los políticos, que es el punto donde esta se vuelve lo otro que si misma; es decir, un problema moral que, debido a la disociación que necesariamente introduce la ambivalencia constitutiva (digamos que como costo cognitivo de la 
adecuación psicológica), no parece encontrar en este planteo las condiciones para una solución política.

\section{Conclusiones}

Como primera conclusión de este trabajo señalamos que, a pesar de la difundida percepción social en torno a la politización creciente y cabal de los jóvenes del discurso hegemónico ligado a la 'consagración de la juventud' (Vázquez, 2013) y de los cambios positivos en los significados y valoraciones de la política entre los jóvenes que han participado de nuestro estudio, encontramos aún una baja disposición hacia la política en todas las clases sociales. No obstante, destacamos que entre los jóvenes de clase alta la disposición hacia la política alcanza un porcentaje más alto que en el resto para la participación en el futuro, y que si bien la elección predominante en cuanto al ámbito recae -al igual que en las clases media y baja- en las instancias sociales (movimientos) más que en las políticas partidistas (partidos), la diferencia entre ellas se achica notablemente y se vuelve no significativa para la disposición potencial.

En el contexto argentino reciente, esta mayor articulación de instancias mencionadas podría interpretarse de modo general como efecto del giro dado en la relación entre movimientos y partidos políticos en la Argentina en los primeros tiempos del kirchnerismo que, como emergente de la crisis del sistema político -tal como señalan Pérez y Natalucci (2012)-, desarrolló la estrategia de fundar transversalidad (Torre, 2005), absorbiendo bajo un gran paraguas partidario a las organizaciones de todo el espectro ideológico, recreando así "una gramática movimientista" (Pérez y Natalucci, 2012, p. 11).

Es cierto que dicha gramática tiene mayor visibilidad en los sectores populares; sin embargo, parece recrearse con éxito creciente en los modos de hacer política y establecer alianzas también en la clase alta (una parte de ella incluida en el mismo 'paraguas' o en desprendimientos del mismo, otra en el de 'la oposición'. Aquí, las asociaciones corporativas logran construir más consenso y legitimidad utilizando una imagen que articula rasgos de organización civil y movimiento ciudadano en una propuesta partidaria de baja densidad colectiva e histórica (y en la cual la distancia entre 'movimiento' y 'partido' es licuada).

Para comprender los datos que señalaban la mayor disposición hacia la política de los jóvenes de clase alta, hemos abordado el análisis de entrevistas transponiendo la noción de ambivalencia constitutiva (Kriger, 2010) en términos bourdieuanos, en tanto 'buena voluntad cultural' y 'deber de la política' (Bourdieu, 1979). Allí 
pusimos el ojo en los sentidos atribuidos a la política y a su valoración: nuestra hipótesis inicial refería a la tensión entre pensamiento político e imperativo moral, por lo cual es de suma importancia la distinción hallada entre 'la política' y 'los políticos' en los argumentos de nuestros entrevistados, en contraste con la visión negativa total que encontramos en investigaciones realizadas durante el período inmediatamente poscrítico (Kriger, 2007). Allí, la política aparecía como la fuente misma de corrupción ('mancha todo lo que toca'), ante la cual si bien los jóvenes estaban interesados en participar de la reconstrucción del país no contaban con la principal herramienta para ello, al menos en sociedades democráticas (la política). En cambio, ahora, al poder discriminar entre el ideal abstracto (republicano) y las prácticas reales y situadas (históricas), nuestros entrevistados logran abrir el horizonte y habilitar un desafío generacional y propio, en que la tensión entre el 'deber de la política' y la 'buena voluntad cultural' -como expresiones de la autopercepción de un porvenir de clase dirigente- hacen albergar en ellos una valoración positiva de la política, que inmediatamente se revela como abstracta al tropezar con la valoración negativa de la práctica política y los políticos reales, con base en el egoísmo y la 'viveza personal'.

De esta manera se llega a la paradoja de postular una política sin políticos, fórmula que parece resultado de la implosión del conflicto, contenido bajo la forma de la coexistencia o conciliación, por el esquema de pensamiento de ambivalencia constitutiva (Kriger, 2010). Pero cuando el 'bien común' es reducido a un imperativo moral, restringiendo su carácter histórico-político -que en última instancia refiere al problema de la legitimidad y la legitimación-, lo social se percibe como un territorio de iguales en armonía y no como una arena de lucha entre desiguales. Solo tomando conciencia de eso se puede desarmar el dilema egoísmo/altruismo y mostrar su limitación moral como matriz de la política. Porque, más allá de la oposición abstracta entre lo privado delimitado al individuo -como sujeto del egoísmo-y lo público totalizado en la comunidad, la nación, etcétera -como objeto de altruismo-, lo social se hacer real en pertenencias parciales que refieren a diversos niveles y dimensiones de la experiencia material. En este marco, las clases sociales difieren de los grandes colectivos, aunque pueden también desarrollar, en tanto clases movilizadas (Bourdieu, 1984), conciencia, identidad (e incluso lealtad) y construir un nos-otros con quienes compartir intereses y necesidades, diferentes a 'los otros'. Un índice de ello podría encontrarse en la movilización de ciertas fracciones de la clase alta argentina en la última década a favor de sus intereses de clase 'ampliados', siendo un hito 'el conflicto del campo' de $2008 .^{6}$

6 Nos referimos al conflicto entre el gobierno nacional y los productores rurales en 2008 en torno a las 
Ahora bien, si la nación es una 'comunidad imaginada' (Anderson, 1993) a través de sofisticados dispositivos culturales, la sociedad es una comunidad vivida que se construye cotidiana e históricamente a través de pactos, contratos sociales, violencia simbólica o abierta (según se vea), pero siempre en conflictividad. De modo que aun si aceptáramos que el 'buen' ciudadano político no debe confundir/ anteponer su bienestar particular al 'bien común', antes aparece el problema de establecer qué es el 'bien común', que no es autoevidente ni natural ni igual para/ desde todas las posiciones de agentes, grupos y clases sociales. El bien común no designa un único significado a priori, sino que es una construcción imaginada de la 'cosa pública' en permanente disputa: es en sí mismo arena de luchas, que si bien en las repúblicas liberales tiene como fundamento y como horizonte la igualdad del género humano, se construye en cada presente entre agentes sociales desiguales. En el marco de la vida de cada uno de ellos -que se va ampliando desde la familia a través de procesos de socialización, pero que nunca llega a ser 'la sociedad' en su totalidad- son los intereses y valores de su grupo y clase los que aparecen más ligados a los contenidos del bien común.

De ahí la importancia del pensamiento histórico y político (Kriger, 2011) que, a través del desarrollo de la autoconsciencia y la reflexividad, permite acceder a una conciencia de la propia posición en el juego social y a una comprensión multiperspectiva del mismo (Carretero y Kriger, 2011), a partir de lo cual el diálogo parte del 'desacuerdo' (Rancière, 1996). Solo entonces la desigualdad real de lo social se revela como injusta, porque al contradecir el ideal básico de la democracia pone en jaque el pilar del bien común, algo que evita el discurso de los jóvenes al no hacer referencia a las luchas que jalonan la sociedad en torno a la distribuciónapropiación desigual 'del poder y la riqueza'. De hecho, interpretamos que los elementos morales del esquema de pensamiento que hemos denominado ambivalencia constitutiva, evitan el conflicto cognitivo y se imponen sobre la aptitud para pensar políticamente.

En términos bourdieuanos, entendemos que en el discurso de estos jóvenes de clase alta la política es pensada bajo la forma dramática de la alodoxia (Bourdieu, 1979), reconocimiento equívoco de problemática consistente aquí en aplicar esquemas morales a problemas políticos, 'resolviéndolos' en términos de conductas

retenciones de la producción agraria. Este episodio tuvo un impacto político que dividió a la opinión pública y contó con amplia difusión mediática, logrando resonancias de otros momentos históricos. Entre nuestros entrevistados de clase alta en esta escuela en particular, cercana a la zona rural más rica de la Pampa húmeda, estos hechos forman parte de su memoria generacional, ya que muchos de ellos participaron junto a sus padres de cortes de rutas y medidas de fuerza, fijando un hito biográfico que enraíza su identidad de clase. 
morales (egoísmo, ganancia, viveza personal, interés propio). En este punto, y en relación con la hipótesis referida a la formulación de las tensiones entre lo individual y lo colectivo en la idea de la política, el orden social no tiene estatus propio más que bajo la forma tributaria de la concepción de la sociedad como sumatoria de individuos, donde el 'egoísmo', 'la viveza personal', el 'interés propio' deben ser superados por la idea del bien común. Los entrevistados seńalan que si cada uno "deja de lado el interés personal", y "hace lo que debe", se llega al "bien común". $\mathrm{Al}$ concebir la sociedad como una sumatoria de individuos, se naturalizan las relaciones entre las clases -que no se conciben en tanto tales-, siendo el objetivo primario realizar una reforma moral individual que habilite la posibilidad de una participación política futura. De modo general, los ciudadanos, pero sobre todo los políticos o los 'dirigentes' como categoría con la cual los entrevistados se identifican al proyectarse en un futuro, son señalados como aquellos que deberían dejar de lado su propio interés y centrarse en el de toda la sociedad (el bien común), como si no existieran intereses objetivos antagónicos intrínsecos entre las clases sociales, y las diferencias pudiesen ser resueltas con buena voluntad. Es interesante notar que ello presupone de modo implícito una contradicción básica entre el individuo y la comunidad que debe ser superada, por un lado, a través de la educación moral 'de los ricos' para cumplir con su función política de clase dirigente, y por el otro, con la educación moral de los otros, 'los pobres', para cumplir con su función ciudadana de pueblo representado, que debe saber elegir a sus buenos gobernantes, temas recurrentes en las entrevistas. Esto neutraliza la tensión en términos de clases sociales, de orden político, y la transforma en un problema moral (de ahí la filantropía y el asistencialismo), de modo que la propia condición de clase dominante queda naturalizada negándose a sí misma en sus condiciones sociales, lo mismo que se niegan las condiciones sociales de las demás clases. De esa manera, la sociedad, y la política de los políticos, es mirada desde arriba, siendo la participación política en el futuro un deber moral propio de un porvenir de clase.

Con este trabajo esperamos haber contribuido al análisis de las variaciones que la incorporación del capital entre las clases juega a la hora de fundamentar la relación de los jóvenes con la política, con sus disposiciones y esquemas de pensamiento, como agentes activos de su sociedad. 


\section{Referencias bibliográficas}

Aguilera Ruiz, O. (2009). Los estudios sobre juventud en Chile: coordenadas para un Estado del Arte. Última Década 17 (31), 109-127.

(2011). Acontecimiento y acción colectiva juvenil. El antes, durante y después de la rebelión de los estudiantes chilenos en el 2006. Propuesta Educativa 1 (35), 11-26.

Alvarado, S., Vommaro, P. (2010). Jóvenes, cultura y política en América Latina: algunos trayectos de sus relaciones, experiencias y lectura (1960-2000). Buenos Aires: Clacso.

Anderson, B. (1993). Comunidades imaginadas. México D. F.: Fondo de Cultura Económica.

Bonvillani, A., Palermo, A., Vázquez, M., Vommaro, P. (2010). Del Cordobazo al kirchnerismo. Una lectura crítica acerca de los periodos, temáticas y perspectivas de los estudios sobre juventudes y participación política en Argentina. En S. Alvarado y P. Vommaro, Jóvenes, cultura y politica en América Latina: algunos trayectos de sus relaciones, experiencias y lectura (1960-2000) (pp. 21-54). Buenos Aires: Clacso.

Bourdieu, P. (1974). Avenir de classe et causalité du probable. Revue française de sociologie $\mathrm{XV}, 3-42$.

(1977). Sur le pouvoir symbolique. Annales 32 (3), 405-411.

(1979). La distinction. Critique sociale du Jugement. París: Minuit.

(1984). Espace social et genèse des classes. Actes de la recherche en sciences sociales 52-53, 3-14.

[1980] (1990a). Cultura y política. Sociología y cultura. México D.F.: Grijalbo.

[1978] (1990b). La “juventud” no es más que una palabra. Sociología y cultura. México D.F.: Grijalbo.

(1993). La misère du monde. París: Seuil.

(1994). Un acte desinteresse est-il possible?. Raisons pratiques. París: Seuil.

Bourdieu, P., Darbel, A., Rivet, J. P, Seibel, C. (1963). Travail et travailleurs en Algérie. París: Mouton.

Brandäo, Z. (2009). Por una heterodoxia controla. En M. E. Martínez, A. Villa y V. Seoane (coords.), Jóvenes, elección escolar y distinción social (pp. 79-105). Buenos Aires: Prometeo.

Carretero, M., Kriger, M. (2004). ¿Forjar patriotas o educar cosmopolitas? El pasado y el presente de la historia escolar en un mundo global. En M. Carretero y J. Voss (eds.), Aprender y enseñar la historia (pp. 71-98). Buenos Aires: Amorrortu.

(2011). Historical representations and conflicts about indigenous people as national identities. Culture and Psychology 17 (2), 177-195.

Chaves, M. (2005). Juventud negada y negativizada: representaciones y formaciones discursivas vigentes en la Argentina contemporánea. Última Década 13 (23), 9-32.

, coord. (2009). Estudios sobre juventudes en Argentina. Hacia un estado del arte/2007. La Plata: Edulp, Reija. 
Coleman, J., Hendry, L. (2003). Política, altruismo y acción social. Psicología de la adolescencia. Madrid: Morata.

Dávila, Ó., Ghiardo, F., Medrano, C. (2006). Los desheredados. Trayectorias de vida y nuevas condiciones juveniles. Valparaíso: CIDPA.

De Laire, F. (2001). ¿Identidad juvenil?: la insoportable levedad del ser (aportes para renovar el marco teórico de los estudios sobre juventud). Persona y Sociedad XV (2), 175-184.

Del Cueto, C. (2007). Los únicos privilegiados. Buenos Aires: UNGS-Prometeo.

Delfino, G., Zubieta, E. (2011). Interés y preferencias políticas en estudiantes universitarios de la Ciudad de Buenos Aires. Perspectivas 8, 30-39.

Delval, J. (2006). Hacia una escuela ciudadana. Madrid: Morata.

Dreyer, C., Ocampo, J. (2013). ¿Qué es un movimiento social fuerte? Conceptualización de la noción de fortaleza y aplicación al caso del movimiento estudiantil 2002-2011 en Chile. Última Década 21 (38), 91-108.

Duarte, C. (2005). Trayectorias en la construcción de una sociología de lo juvenil. Persona y Sociedad XIX (3), 163-82.

Dukuen, J. (2013a). Habitus y dominación. Para una crítica de la teoría de la violencia simbólica en Bourdieu. Tesis doctoral, Facultad de Ciencias Sociales, Universidad de Buenos Aires.

(2013b). Otros territorios: una discusión sobre la relación entre cultura y política desde Bourdieu aplicable al estudio de jóvenes escolarizados. Revista Argentina de Estudios de Juventud 1 (7), 105-25.

Feixa, C. (2000). De jóvenes y tribus. Barcelona: Ariel.

García Canclini, N. (1999). La globalización imaginada. Buenos Aires: Fondo de Cultura Económica.

Gayo, M. (2013). La teoría del capital cultural y la participación cultural de los jóvenes. El caso chileno como ejemplo. Última Década 21 (38), 141-171.

Gordon, A., Moguillansky, M. (2003). Una mirada sobre la participación política estudiantil: el caso de la UBA. Ponencia en el Congreso Latinoamericano de Educación Superior en el Siglo XXI, San Luis.

Hahn, C. L. (2006). Citizenship education and youth attitudes: Views from England, Germany, and the United State. En H. Ertl (ed.), Cross-National Attraction in Education: Accounts from England and Germany. Didcot: Symposium Books.

Kriger, M. (2007). Historia, identidady proyecto: un estudio de las representaciones de jóvenes argentinos sobre el pasado, presente y futuro de su nación. Tesis doctoral, Flacso-Argentina.

(2010). Jóvenes de escarapelas tomar. Escolaridad, comprensión histórica y formación política en la Argentina contemporánea. La Plata: Edulp, CAICYT-Conicet.

(2011). La enseñanza de la historia reciente como herramienta clave de la educación política. Persona y SociedadXXIV (3), 29-52. 
(2012). La invención de la juventud, entre la muerte de las naciones y su resurrección. En M. Kriger (comp.), Juventudes en América Latina: abordajes multidisciplinares sobre identidades, culturas y politicas del siglo XX al siglo XXI (pp. 5-31). Buenos Aires: CAICYT-Conicet.

(2013). Reflexiones acerca de la despolitización y la politización juvenil en la Argentina, entre la desestructuración y la reestructuración del Estado Nacional. Dossier: Juventudes politicas. Sociales en Debate 6, 25-32.

Kriger, M., Bruno, D. (2013). Youth and politics in the Argentine context: Belief, assessment, disposition, and political practice among young students (Buenos Aires, 2010-12). Les c@hiers de psychologie politique 22. Disponible en http://lodel.irevues.inist.fr/cahierspsychologiepolitique/index.php?id=2365 [enero 2013].

Kriger, M., Dukuen, J. (2012). Clases sociales, capital cultural y participación política en jóvenes escolarizados. Una mirada desde Bourdieu. Revista Question 1 (35), 317-327.

(2013). La buena voluntad. Sentido y disposiciones hacia la política en jóvenes escolarizados de clase alta. Ponencia en el IV Congreso Internacional de Investigación Educativa, UNComa.

Kriger, M., Fernández Cid, H. (2011). Los jóvenes y la construcción del "ciudadano ideal". Una aproximación a las acciones y relatos de ciudadanía de jóvenes escolarizados de Buenos Aires. Ponencia en el III Congreso Internacional de Investigación-Facultad de Psicología, UNLP.

Lane, J. (2006). Bourdieu's Politics. London: Routledge.

Lefort, C. (1992). El arte de escribir y lo politico. Barcelona: Herder.

Margulis, M. (1996). La juventud es más que una palabra. Buenos Aires: Biblos.

Martínez, M. E., Villa, A., Seoane, V. (2009). Parte I: Argentina. En M. E. Martínez, A. Villa, V. Seoane (coords.), Jóvenes, elección escolar y distinción social (pp. 27-76). Buenos Aires: Prometeo.

Nordmann, C. (2010). Bourdieu y Rancière, la política entre sociología y filosofía. Buenos Aires: Nueva Visión.

Núñez, P. (2012). Comportamientos políticos juveniles desde la transición democrática hasta la "toma" de escuelas. En M. Kriger (comp.), Juventudes en América Latina: abordajes multidisciplinares sobre identidades, culturas y políticas del siglo XXalsiglo XXI (pp. 78-109). Buenos Aires: CAICYT-Conicet.

Pérez, G., Natalucci, A. (2012). El kirchnerismo como problema sociológico. En G. Pérez y A. Natalucci (comps.), Vamos las bandas. Organizaciones y militancia kirchnerista (pp. 7-26). Buenos Aires: Trilce.

Rancière, J. (1996). El desacuerdo. Buenos Aires: Nueva Visión.

Reguillo, R. (2000). Emergencia de culturas juveniles. Buenos Aires: Norma.

Rosanvallon, P. (2006). La contrademocracia. Buenos Aires: Manantial. 
Ruiz Silva, A. (2009). La nación en los márgenes. Tesis doctoral, Ciencias Sociales, FlacsoArgentina.

Saintout, F., comp. (2010). Jóvenes argentinos: pensar lo politico. Buenos Aires: Prometeo. (2012). La invención de la juventud, entre la muerte de las naciones y su resurrección. En M. Kriger (comp.), Juventudes en América Latina: abordajes multidisciplinares sobre identidades, culturas y politicas del siglo XX al siglo XXI (pp. 5-31). Buenos Aires: CAICYT-Conicet.

Sidicaro, R., comp. (1998). La Argentina de los jóvenes: entre la indiferencia y la indignación. Buenos Aires: Unicef.

Svampa, M. (2001). Los que ganaron. La vida en los countries y barrios privados. Buenos Aires: Biblos.

Torre, J. C. (2005). La operación política de la transversalidad. El presidente Kirchner y el Partido Justicialista. En E. Baistrocchi et al., Argentina en perspectiva. Reflexiones sobre nuestro pais en democracia. Buenos Aires: UTDT.

Urresti, M. (2000). Paradigmas de la participación juvenil: un balance histórico. En S. Balardini (comp.), La participación social y politica de los jóvenes en el horizonte del nuevo siglo. Buenos Aires: Clacso, ASDI.

Vázquez, M. (2010). Socialización politica y activismo. Carreras de militancia politica de jóvenes referentes de un movimiento de trabajadores desocupados. Tesis doctoral, Facultad de Ciencias Sociales, Universidad de Buenos Aires.

(2012). Liderazgo y compromiso político desde una mirada diacrónica: una aproximación a tres generaciones de jóvenes militantes en movimientos de desocupados. Revista Utopia y Praxis Latinoamericana 17 (57), 49-63.

(2013). En torno a la construcción de la juventud como causa pública durante el kirchnerismo: principios de adhesión, participación y reconocimiento. Revista Argentina de Estudios de Juventud 1 (7), 1-25.

Vázquez, M., Vommaro, P. (2008). La participación juvenil en los movimientos sociales autónomos. El caso de los Movimientos de Trabajadores Desocupados (MTDs). Revista Latinoamericana de Ciencias Sociales, Niñez y Juventud 6 (2), 485-522.

Vommaro, P. (2013). Las relaciones entre juventudes y políticas en la América Latina contemporánea: una aproximación desde los movimientos estudiantiles. Sociedad 1 (32), 127-144.

Wacquant, L., comp. (2005). El misterio del ministerio. Pierre Bourdieu y la politica democrática. Barcelona: Gedisa.

Zibechi, R. (2003). Los movimientos sociales latinoamericanos: tendencias y desafíos. $O b$ servatorio Social de América Latina 1 (9), 185-188.

Ziegler, S. (2004). La escolarización de las elites. En G. Tiramonti, La trama de la desigualdad educativa (pp. 73-99). Buenos Aires. Manantial. 